\title{
QUANDO A CRIANÇA NASCE DOENTE: A SUBJETIVIDADE DO INFANTE E AS RELAÇÕES FAMILIARES
}

WHEN THE CHILD IS BORN SICK: THE SUBJECTIVITY OF THE INFANT AND THE FAMILY RELATIONSHIP

CUANDO EL NIÑO NACE ENFERMO: LA SUBJETIVIDAD INFANTIL Y LAS RELACIONES FAMILIARES

\author{
Bruna Rocha de Almeida* \\ Paula Melgaço ${ }^{* *}$
}

\begin{abstract}
RESUMO
A presença de patologia orgânica grave na criança permite investigar uma das modalidades pelas quais a constituição subjetiva sofre seus efeitos. Nesses casos, a condição psíquica, longe de ser consequência direta da patologia orgânica, configura um complexo jogo identificatório imaginário da relação que o campo social (em especial os cuidadores) estabelece com a criança. Muitas vezes, os pais de crianças que nascem com doenças graves não conseguem ver um futuro para elas e passam a tratá-las como impotentes: como sem o poder de realizar o desejo parental. Esse fato pode resultar num desinvestimento de libido parental sobre essas crianças e em prejuízos para a sua constituição subjetiva. Este trabalho faz uma elucidação teórica sobre a incidência de uma doença grave na infância. Para melhor compreensão, foi usado um caso clínico como exemplo.
\end{abstract}

Palavras-chave: Doença na infância. Constituição psíquica. Família.

\begin{abstract}
The presence of severe organic disease in children allows for investigation into one of the ways in which the subjective constitution suffers its effects. In such cases, the psychic condition, far from being a direct consequence of organic pathology, represents an identification of imaginary interplay very complex of the relationship that the social field (especially caregivers) establishes with the child. Often, parents of children born with serious diseases cannot see a future for them and begin to treat them as impotent, as someone without the power to realize parental desires. This fact can result in a divestment of parental libido on these children and in damages to hers subjective constitution. This paper makes a theoretical elucidation on the
\end{abstract}

$\overline{\text { Texto submetido em } 31}$ de maio de 2013 e aprovado para publicação em 21 de maio de 2015.

Doutoranda e mestra em Psicologia pela UFJF; psicóloga graduada pela UFMG. Endereço: Rua José Lourenço Kelmer, 1200 -

São Pedro, Juiz de Fora-MG, Brasil. CEP: 36036-330. Telefone: (32) 99138-1598. E-mail: bruna.r.almeida@gmail.com.

** Mestranda em Psicologia pela PUC Minas; psicóloga graduada pela UFMG. Endereço: Rua Xapuri, 450, ap. 302 - Grajaú, Belo Horizonte-MG, Brasil. CEP: 30431-214. Telefone: (31) 98461-2296. E-mail: paulamelgaco.psi@gmail.com. 
incidence of serious illness in childhood. For a better understanding was used a clinical case as example.

Keywords: Disease in childhood. Psychic constitution. Family.

\section{RESUMEN}

La presencia de patología orgánica grave en los niños permite investigar una de las formas en que la constitución subjetiva sufre sus efectos. En estos casos, la condición psíquica, lejos de ser una consecuencia directa de la patología orgánica, configura un complejo juego identificador imaginario de la relación que el campo social (especialmente los cuidadores) establece con el niño. A menudo, los padres de los niños nacidos con enfermedades graves no pueden ver un futuro para ellos y empiezan a tratarlos como impotentes: como sin el poder para llevar a cabo el deseo parental. Esto puede dar lugar a la desinversión de la libido parental sobre estos niños y a daños a su constitución subjetiva. En este trabajo se hace una aclaración teórica sobre la incidencia de una enfermedad grave en la infancia. Para una mejor comprensión se utilizó como ejemplo un caso clínico.

Palabras clave: Enfermedades en la infancia. Constitución psíquica. Familia.

\section{QUANDO A CRIANÇA NASCE DOENTE: A SUBJETIVIDADE DO INFANTE E AS RELAÇÕES FAMILIARES}

$\bigwedge \begin{aligned} & \text { diferenciação entre a maturação do organismo e a constituição subjetiva } \\ & \text { nem sempre foi considerada na cultura. Mesmo as teorias psicológicas } \\ & \text { assimilaram a estrutura simbólica em que a subjetivação se processa e }\end{aligned}$ vigora aos mesmos princípios biológicos da estruturação orgânica, da qual a primeira seria mera extensão. Entretanto, hoje sabemos que o desenvolvimento humano não sobrevém de meros automatismos desencadeados apenas pelo passar do tempo e seus efeitos na maturação do organismo. O desenvolvimento está vinculado à constituição psíquica e, dessa forma, ao laço que se estabelece entre o bebê ou a criança e o Outro (Jerusalinsky, 2002).

A presença de patologia orgânica grave na criança permite investigar uma das modalidades pelas quais a constituição subjetiva sofre seus efeitos. Nesses casos, a condição psíquica, longe de ser consequência direta da patologia orgânica, configura um complexo jogo identificatório imaginário da relação que o campo social (em especial os cuidadores) estabelece com a criança. 
A constatação de uma patologia orgânica grave como marca inaugural da existência de uma criança produz prejuízos na construção e estabelecimento dos laços parentais imprescindíveis à subjetivação. A patologia coloca em risco a edificação do ideal dos pais em relação ao filho doente porque, a seu caráter de dependência, a infância da criança sofre o acréscimo da impotência: a doença, quando presente em um ser ainda por se fazer, conota a dificuldade de ser considerada como intercorrência passageira. Por um lado, a criança já aparece doente sem antes ter sido saudável. Por outro lado, para além de seu estado de saúde, seu estado produz lesão evidente no saber parental. Mesmo sendo de ordem fantasmática, a doença do filho incide como lesão ao saber dos pais, pois estes são confrontados com sua própria insuficiência para exercerem suas funções de cuidado do neonato. Necessitarão do saber médico como uma muleta para a adequada criação do recém-nascido. Com bebês que apresentam problemas somáticos graves, surge nos pais o temor de fomentar ilusões e a desilusão: ao mesmo tempo em que lhes resulta impossível produzir uma aposta de futuro para o filho, apresentam dificuldade em produzir uma historização do bebê. $\mathrm{O}$ que está perdido aí é o ponto de amarra que permita a extensão, o estiramento do fio do desejo, pelo qual possa ser tecida uma série simbólica da vida desse bebê. Nesse sentido, como indica Pavone e Abraão (2014), um problema no funcionamento orgânico da criança pode tornar-se um entrave à sua constituição e o traço pelo qual será reconhecida pelos seus pais.

Nessas ocasiōes, é comum que a família estabeleça um campo de proteção exacerbado, não apenas evitando ter de enfrentar limites que a condição da criança impõe às expectativas, mas também tornando restrito (de forma não intencional) o contato da criança com o mundo, considerado como perigoso, como algo a ser evitado em prol de uma vida mais longínqua. A consequência é, muitas vezes, uma criança pouco adaptada ao convívio social, insegura e imatura nas relaçôes e com dificuldades de aprendizagem.

Assim, quando uma criança apresenta alguma patologia, esta pode vir a suprimir, no marco de sua constituição, a sua subjetividade, conforme a hipoteca familiar depositada antecipadamente no bebê não foi quitada como desejado. Neste trabalho, será feita uma elucidação teórica sobre a incidência de uma doença grave na infância. Para melhor compreensão, será utilizado um caso clínico como exemplo.

\section{DOENÇA GRAVE NA INFÂNCIA}

Qual a diferença entre doença grave e doença grave na infância? Que propriedade há no infantil para que exista essa diferença? Por que a infância aparece como um diferencial para essa questão? 
Essas perguntas foram respondidas por Vorcaro (1998). A autora enfatiza que, ao pensarmos em infância, faz-se necessário situar duas ordens que são coincidentes, apesar de não serem equivalentes: ao mesmo tempo ocorre a primeira etapa do desenvolvimento do organismo e a lógica de estruturação do sujeito que, como enunciou Freud, são dependentes concomitantes. Por conseguinte, é necessário entender como as ameaças ao desenvolvimento pleno são capazes de incidir sobre a estruturação do sujeito. Nesse sentido, é possível pensar na existência de uma interação de mútua influência entre soma e psique. Freud já defendia essa ideia ao elucidar que o psiquismo não poderia ser reduzido ao plano da consciência (formulação dos processos inconscientes) nem o corpo à porção somática.

O advento do Estado, a partir do séculoXVII configurou uma nova modalidade de funcionamento social que conferiu ao infante um status privilegiado na sociedade, inspirando o sentimento de família (o filho como continuidade da vida para além da morte dos pais) e do futuro da nação. Dessa forma, o que a criança é somente importa em relação ao que ela será no futuro: a possibilidade de ela vir a ser o desejo dos pais e da nação (Vorcaro, 1998). A criança, assim, vale pelo que ela será e sobre ela recai o ideal de seus pais.

Apesar de a estruturação do sujeito não ser orgânica, a doença, principalmente quando representa um risco de morte ou impotência permanente, pode decidir muito da "estruturação do sujeito ao tornar-se o traço prevalente através do qual ele é reconhecido pelos agentes parentais e pelos agentes do seu tratamento" (Vorcaro, 1998, p. 3). Quando nasce doente, a criança idealizada não coincide com a criança concreta, devido à impotência representada pela doença. A condição orgânica, então, pode desmontar o imaginário dos pais que sustentava as hipóteses sobre o seu filho esperado/desejado (Pavone \& Abraão, 2014). Ao constatar que as suas interpretações sobre as manifestações do infante são insuficientes, os pais suspendem seu desejo de filho ideal (Vorcaro, 1998). Ao mesmo tempo, o momento do diagnóstico, mobiliza nos pais intensos sentimentos de impotência e medo diante da possibilidade de morte do filho, bem como de desamparo diante dessa situação (Kruel \& Lopes, 2012).

Nessa perspectiva, muitas vezes, os pais não conseguem ver um futuro para essa criança e passam a tratá-la como impotente: como sem o poder de realizar o desejo parental. Esse fato pode resultar num desinvestimento de libido parental sobre essas crianças, já que na infância a doença significa muito mais que uma enfermidade passageira, é uma lesão que coloca em risco a edificação do ideal parental. Conforme enfatiza Pavone e Abraão (2014), 
O efeito real do déficit orgânico atinge o próprio simbólico, ou seja, a cadeia de significantes nos quais a criança era posicionada provocando a desmontagem do saber parental, atingindo a rede de significações na qual a criança se estruturará como sujeito. (p. 376)

Destaca-se também que a incidência da doença, além de ameaçar a integridade do corpo infantil e convocar o sujeito a uma nova organização psíquica, interfere na rotina e nos hábitos familiares, bem como nos projetos da família (Reze, 2006).

\section{UM POUCO DA HISTÓRIA DE SARA ${ }^{1}$}

Para melhor compreensão deste trabalho, faz-se importante relatar um pouco da história de Sara.

Sara, 9 anos, sexo feminino, chegou ao consultório de Psicologia trazida pela mãe, com a queixa de dificuldade de aprendizagem, além de estar agitada, inquieta e agressiva. A mãe relatou também que Sara ficava bastante nervosa quando lhe diziam "não" e chorava muito quando era contrariada.

De acordo com a mãe, a gestação de Sara foi tranquila até o sexto mês, quando começou a ter enjoo e muita dor, sendo necessário o uso de medicamentos para manter a criança em gestação. Isso ocorreu porque Sara tinha problemas cardíacos e havia parado de se desenvolver.

Sara nasceu no oitavo mês de gestação, pesando $1,9 \mathrm{~kg}$ e medindo 33 $\mathrm{cm}$, durante uma cesariana bastante complicada, pois sua mãe teve início de eclampsia. A criança ficou na incubadora por mais de um mês, a fim de ganhar peso para fazer a cirurgia cardíaca. Sara fez dois cateterismos no primeiro mês de vida, uma cirurgia denominada Jatene com um mês e meio, e outro cateterismo em dezembro de 2008, quando tinha 9 anos.

Tudo isso ocorreu porque Sara nasceu com uma malformação embrionária, denominada cardiopatia congênita, com inversão dos vasos da base e comunicação intraventricular. Isso resultava no fato de o sangue rico em oxigênio deixar de sê-lo por estar se comunicando com o sangue pobre em oxigênio e rico em gás carbônico. Assim, o sangue que saía do ventrículo esquerdo, que deveria levar oxigênio para os tecidos do corpo, estava levando uma quantidade abaixo do necessário.

O tecido, sem a quantidade de oxigênio adequada, tende a morrer. Em geral, os tecidos do corpo não morrem de imediato quando há falta de oxigenação, 1 Sara é um nome fictício. 
porque temos a capacidade de obter oxigênio por outras vias. No entanto isso não ocorre com o tecido do sistema nervoso central (SNC). Dessa forma, é provável que Sara tenha ficado com sequelas. Fazia-se importante investigar se, mesmo após a cirurgia, ainda havia uma deficiência na oxigenação cerebral da criança. A ressonância magnética já havia sido solicitada pelo médico responsável, no entanto, como seria feita pelo SUS, ainda não fora autorizada, embora estivesse na fila de espera.

Além do exposto acima, a criança apresentou atraso no desenvolvimento da linguagem e teve acompanhamento com fonoaudiólogo por quatro anos. Além disso, os dentes de Sara nasceram danificados e, por isso, fez tratamento ao longo de cinco anos, num centro odontológico de uma universidade pública. $\mathrm{O}$ encaminhamento para o serviço de Psicologia foi proposto pelos estudantes de Odontologia. Vale ressaltar que Sara já havia passado por outros atendimentos psicoterápicos antes de se inscrever na clínica-escola da universidade em questão. Não há informações consistentes sobre esses atendimentos.

\section{O LUGAR DO DESEJO DOS PAIS QUANDO O BEBE NASCE DOENTE}

Antes de a criança nascer, já existe uma história e uma família que a espera. Dessa forma, não é um lugar ausente de significações que espera pelo bebê (Brauer, 1994) e será por ele ocupado. O lugar que a criança ocupará em relação aos demais membros da família, as condições de gestação e do nascimento, enfim, tudo é inundado pelos desejos dos pais e por eles investido de significações em razão da história de suas vidas e do contexto familiar no qual estão inseridos (Faria, 1994). Por isso é tão difícil para os pais, em especial para a mãe, lidar com a notícia de que o filho tem uma patologia grave: eles precisam lidar com a perda/luto do bebê desejado, o que mobiliza intensos afetos e ideias depressivas (Battikha, Faria, \& Kopelman, 2007). Destaca-se, contudo, que, embora o luto seja doloroso, ele é necessário para o processo de aceitação do filho real (Tavares, Carvalho \& Pelloso, 2014).

Segundo Lacan (1978), o lugar do sujeito já está inscrito no momento do seu nascimento, mesmo que apenas sob a forma de seu nome próprio, sendo que o lugar que esse nome próprio ocupa é permeado pelo desejo e ideais da família que escolhe o nome. Ao nascer com uma patologia orgânica grave, é dada à criança a nomeação patológica, perdendo a singularidade do nome próprio anteriormente lhe atribuído.

No caso de Sara, não seria diferente. Conforme sua mãe conta, o nome de Sara foi escolhido pelas irmãs, que nela depositaram todo o desejo de ter um lindo 
bebê na família. No entanto, com a descoberta da doença da criança, seu nome foi ligado a outro significado, e a carga da doença se mostrou. Ela então era a "Cardíaca" da família, passando a ser vista através de sua patologia. É assim que a mãe anunciou na primeira sessão de psicoterapia e em vários outros momentos: "Ela não pode fazer isso, é cardíaca". "Temos de protegê-la, é cardíaca." Dessa forma, na maior parte do tempo, a expressão "ela é cardíaca" foi usada como substituta da palavra "Sara". Parece que a mãe evitava, de forma inconsciente, dizer o nome da filha, passando a falar de sua patologia. Talvez porque ser vista através de sua doença fosse uma forma da mãe de inscrever a filha "em algum lugar de pertinência e reconhecimento a partir do seu diagnóstico, como se assim pudesse dizer a que família pertence esse bebê, com quem se parece, qual será o seu futuro" (Battikha, Faria \& Kopelman, 2007, p. 20).

Em alguns casos de crianças que nascem com doença orgânica grave, essa questão pode ser ainda mais complexa, conforme nos explica Vorcaro (1997):

A nomeação diagnóstica adquire tamanha pregnância que chega a destituir o nome próprio da criança, que é substituído pela identidade social conferida pelo nome da síndrome em que a ciência médica localiza, define e torna transparente a estranheza causada por ela. Estabelece-se assim uma nova filiação, já que a paternidade, dada pelo nome da síndrome baliza, referencia e justifica os atos, falas e condutas da criança, deslocando-a da possibilidade de situar-se a partir de sua ordem própria de filiação. Tomar a criança como "aquela Rett", "ele é pc", "Meu filho é Asperger" é estabelecer e determinar constrangimentos a sua subjetivação (p. 36).

Essa questão é explicada pelo fato de que a antecipação imaginária (configurada com base nos ideais familiares e sociais) traduz-se na possibilidade de realizar novas ofertas ao bebê, ou seja, a mãe não produz simplesmente antecipações imaginárias, ela também as coloca em ato nos cuidados que dirige ao bebê, produzindo antecipações funcionais (Jerusalinsky, 2002). No caso de bebês que nascem com um quadro de patologia orgânica grave, o que pode ocorrer é o casal parental, inundado pelo diagnóstico da doença do filho e pelo prognóstico não favorável, considerar que a antecipação imaginária se tornou falida e, assim, não realizar a antecipação funcional, deixando o bebê privado de estimulações necessárias ao desenvolvimento.

O saber parental, que muito serviu aos cuidados das filhas mais velhas que Sara, de nada mais servia aos olhos da mãe. Como ela contou, seguiu prontamente todas as orientações e propostas dos profissionais de saúde. Não fez "como outras mães que pensaram que sabiam cuidar de seus filhos [...] agora lá estão aqueles marmanjos fazendo xixi nas calças e sem saber conversar direito", falando isso 
ao comparar a filha às outras crianças que fazem tratamento no hospital que ela frequenta, demonstrando a necessidade de utilizar o saber médico, ao mesmo tempo em que tornava implícito o fracasso do saber parental para cuidar da filha.

Além da singularidade adormecida, há também uma importante questão de não responsabilização daquele que carrega a doença. De acordo com Carter e McGoldrick (1995), a tendência da família de ver a pessoa doente como morta (ou quase morta) pode desencadear respostas não adaptativas que privam o enfermo de importantes responsabilidades. O resultado final dessas respostas pode ser uma completa alienação da pessoa, no caso da criança, de suas possíveis responsabilidades, desde as mais simples como o cuidado com os materiais escolares ou com os brinquedos, às mais significativas como o cuidado com sua saúde e com sua própria vida.

Ainda segundo Carter e McGoldrick (1995), a ideia do "poderia acontecer" das doenças orgânicas graves pode levar a família a superproteger o membro doente, que garante com isso significativos ganhos secundários. Essa situação é particularmente relevante no caso de crianças doentes. Na tentativa de privá-lo de quaisquer ameaça de perigo, o infante é envolvido em uma redoma imaginária, separado e protegido de quaisquer eventos externos que, supostamente, podem lhe causar algum mal e desencadear ou otimizar um processo sintomático e de sofrimento. Em uma fala da mãe de Sara, percebe-se bem como ela foi privada de várias estimulações que seriam consideradas comuns para um bebê sadio e importantes ao bom desenvolvimento: "Não deixávamos [a mãe e o pai] Sara no chão [...] ela ficava no colo ou no carrinho o tempo todo para que não corresse risco de machucar".

Não se pode negar que há uma limitação real do corpo, que torna imprescindível a ajuda do outro para determinadas atividades. No entanto a criança pode ser colocada numa posição de passividade tal que prejudique o seu desenvolvimento. Essa passivação não seria decorrente da patologia orgânica em si, mas da forma como se deu a inscrição da criança como sintoma no laço paisfilho (Jerusalinsky, 2002).

Em Sara percebemos que uma proporção considerada de suas dificuldades cognitivas e de percepção de si poderiam ter sido decorrentes tanto da forma como se estabeleceram as relaçôes familiares como também da necessidade de tratamentos contínuos que fizeram com que o tempo que teria sido destinado à estimulação, à escolarização e às brincadeiras fosse utilizado nas filas de hospitais e ambulatórios e nas macas dos médicos. 


\section{SOBRE DESENVOLVIMENTO DA CRIANÇA}

O atraso no desenvolvimento do sujeito pode ser resultado, dentre outros fatores, de uma resistência de se avançar para um estágio posterior ou do excesso de gratificação em um determinado estágio, que acabe por indicar à criança que não lhe seria proveitoso o caminho para frente. Nesse sentido, ao mesmo tempo em que a relação estabelecida na família pode favorecer a posição passiva da criança diante de seu processo de desenvolvimento, a criança também tem responsabilidade pela escolha de assumir tal postura que, de certa forma, pode ser mais cômoda, além trazer alguns benefícios secundários à sua doença como a atenção e a proteção dos pais e de todo o grupo familiar. Sara desfrutava, por exemplo, das vantagens de ser um bebê aos olhos da mãe (como será visto mais adiante, neste trabalho), não precisando se responsabilizar sequer com os objetos de uso pessoal, ao mesmo tempo em que tudo do que precisava lhe era entregue nas mãos, como as roupas a serem usadas no dia e a comida.

Além disso, quando a criança nasce com uma patologia orgânica grave, a multiplicidade de intervençôes terapêuticas, sejam elas médicas, nutricionais, odontológicas, fisioterápicas, embora necessárias à cura, ou diminuição dos sintomas trazidos pela patologia, fragmentam a possibilidade de a criança se reconhecer como sujeito de desejo, capaz de perceber-se como dotado de vontades e desejos. Isso porque a extensa lista de restrições motoras, sociais e alimentares, alinhada à superproteção parental, resulta numa diminuição considerável das possibilidades de circular no meio social, como faz uma criança desprovida de patologias graves. O resultado é um prejuízo no desenvolvimento emocional, psicomotor e cognitivo.

Em adição, sabemos que o desenvolvimento não é decorrente de simples automatismos desencadeados apenas pelo passar do tempo e seus efeitos na maturação do organismo. $O$ desenvolvimento está vinculado à constituição psíquica e, dessa forma, ao laço que se estabelece a criança e o Outro (Jerusalinsky, 2002). Nesse sentido, instigar o fortalecimento o laço da criança com o Outro, ao mesmo tempo em que propor estimulação diferenciada, pode auxiliar no alcance de um desenvolvimento satisfatório.

\section{A INTERVENÇÃO PSICOTERÁPICA EM CRIANÇAS COM DOENÇAS GRAVES}

Conforme pais ou cuidadores pressupõem que o bebê não é suficientemente capaz para responder, deixam de se aventurar a dirigir antecipações funcionais nos cuidados da vida cotidiana e procuram o psicólogo, e demais profissionais, para endereçar-lhe o futuro de seu filho (Jerusalinsky, 2002). 
Vale lembrar que, ao trabalhar com crianças com doenças graves, o trabalho na clínica psicanalítica não ocorre como na clínica médica: não se toma $o$ sentido da mesma forma, qual seja, no real orgânico do seu corpo. Tampouco consiste em tomar as intervenções como forma de enquadramento da criança às funções e necessidades defendidas socialmente. $\mathrm{O}$ trabalho do psicólogo deve ser pautado na tentativa de se estabelecer uma leitura clínica do sintoma da criança. Para tal objetivo, é preciso perceber o circuito de demanda e desejo no qual o infante está implicado, isto é, deve-se considerar a imagem de seu corpo bem como as inscrições simbólicas que nele foram efetuadas pela fantasia materna (Jerusalinsky, 2002).

Nesse sentido, o clínico deve tentar distinguir o limite estabelecido pela patologia ao desenvolvimento da criança e o que se impóe como limite a partir de um ponto imaginário dos pais que estabelece o que a criança é capaz ou não de fazer. É normal encontrarmos, por exemplo, crianças cujas produções são lidas apenas e unicamente com base na caracterização da doença.

Inclusive há quem diga que de nada vale a intervenção de um psicoterapeuta quando é detectada a presença de um quadro de doença orgânica grave, como nos quadros lesionais ou de malformação congênita. Questionam a atuação do psicólogo pelo fato de a intervenção terapêutica não conduzir à cura da patologia (Jerusalinsky, 2002). No entanto devemos lembrar que a intervenção tem como foco a criança que apresenta a patologia e não a patologia em si.

Nesse sentido, deve-se ter em mente que a intervenção do clínico não está direcionada à reparação ou conserto da criança, colocando-a como objeto a serviço da satisfação de seus pais (Jerusalinsky, 2002). A intervenção deve ser realizada no intuito de permitir à criança construir, atribuir sentido e, ou, ressignificar conteúdos que lhe gerem angústia ou dificuldades; sejam elas emocionais, cognitivas ou psicomotoras, operando uma resposta de significação de sua existência. Ou seja, trata-se de produzir um deslocamento na posição de objeto a ser manejado por um outro, com o intuito de implicar quem diz com o que é dito.

Em uma das sessões psicoterápicas de Sara, a terapeuta levou quatro fantoches para a sala e as pôs sobre a mesa (um de vovó, um de palhaço, um de menina e outro de menino). Sara pegou um fantoche e disse para a terapeuta pegar outro. Depois pegou o outro e disse para a terapeuta fazer o mesmo. Deram nome aos bonecos. Então a terapeuta, dando uma voz a cada um dos bonecos, iniciou um diálogo com os bonecos de Sara. Em determinado momento, ocorreu o seguinte: 
$T-O$ que você faz?

$S-N a d a$.

$T-N a d a ?$

$S-\hat{E}$.

$T-M a s$ eu, por exemplo estudo... E você?

$S$ - Eu não faço nada.

$T-$ Mas por quê?

$S$ - Não posso.

$T$ - Você não pode fazer nada?

$S-E$.

$T-$ Por quê?

$S$ - Minha mãe não deixa.

$T$ - Mas por que sua mãe não deixa?

$S$ - Porque eu não posso fazer esforço?

$T$ - Uai... Você não pode fazer esforço...

$S-E$ E.. o médico falou.

$T$ - Você está dodói?

S-Sim.

(Nesse momento ela tampa seu rosto com os bonecos e continua o diálogo.)

$T-E$ onde que está dodói?

$S-T u d o$.

$T-T u d o$ ?

$S-$ Tudo.

$T-$ Está doendo?

$S$ - Tudo.

T-Onde?

S-Tudo... o bumbum, o pé, o braço, a unha, o cabelo...

$T-O$ que mais está doendo?

$S-T u d o \ldots$

[...]

T-Mas você já melhorou muito... Já está muito mais forte... Já cresceu bastante e está quase ficando boa.

Ela então "abraça" os seus fantoches aos da terapeuta, um por um, como que fazendo um sinal de agradecimento, e para a brincadeira.

Foi a primeira vez que Sara falou sobre sua angústia de não poder fazer as coisas que uma criança de sua idade faz. Ela começou a atribuir sentidos às suas atividades diárias e a ressignificar conteúdos angustiantes. Poder falar, por meio da brincadeira, possibilitou que Sara elaborasse seus sentimentos acerca de sua 
condição orgânica, suas limitaçôes intrínsecas à cardiopatia, e os excessos de cuidados direcionados a ela.

É importante pensar que, além da pessoa doente, há uma família que se envolve, vive e sofre a doença. Assim, os diferentes quadros patológicos, associados aos consequentes sintomas de cada um, implicam na necessidade de ajustamentos específicos numa dada família. Desse modo, há uma importância singular no reconhecimento e auxílio das dificuldades familiares para aceitar, compreender e se ajustar à doença de um membro da família. Ribeiro e Madeira (2006) destacam a importância de haver espaços, como grupos de pais, nos quais os membros da família possam ser ouvidos, compartilhar experiências e ser auxiliados na descoberta de soluções para as dificuldades diárias oriundas da presença de uma criança com doença grave na família. A intervenção psicoterápica, quando possível, também pode ser um instrumento de diálogo e promoção da compreensão dos membros da família de seus novos papéis e funcionamentos. A Psicologia se estabelece, pois,

Como área de conhecimento e atuação imprescindível no acompanhamento de pacientes e de sua família em todas as fases do tratamento, ajudando-os a lidar com os aspectos envolvidos com o diagnóstico de doenças que estão associadas à ideia de morte, sofrimento e solidão (Castro, 2001, p. 47).

Nessa perspectiva, trabalhou-se a forma como a mãe de Sara a percebia e, consequentemente, o lugar em que ela a colocava em seu desejo e em suas fantasias. A mãe da criança a chamava de "meu bebê", ou "bebê da mamãe". Após verificar que a mãe estava pronta para retirar os excessos de gratificações que impediam Sara de se desenvolver e, assim, aceitar o desenvolvimento da filha, a terapeuta falou em uma das vezes que Sara foi chamada de bebê: "Bebê? Uma moça desse tamanho, que já pode até ajudar a mãe nos trabalhos em casa? Não acredito!". Como foi dito de forma leve e estratégica, todos riram. Apesar das gargalhadas, porém, a mãe de Sara passou a chamá-la de "Bebezão". Embora possa não parecer, esse foi um grande avanço. Ora, um bebezão tendia a ser maior que um simples bebê. A mãe, nesse momento, permitiu que a filha cresça, se desenvolvesse. E como num circuito que se retroalimentava, Sara teve avanços no tratamento. A partir de outras intervenções, Sara deixou de ser o "bebezão da mamãe" e passou a ser "mocinha". Enquanto mocinha, ela assumiu algumas responsabilidades (como colocar comida para a cachorra, guardar as vasilhas) e alguns direitos, como ir sozinha à casa da prima, que era sua vizinha. 


\section{MAIS UM POUCO DO TRATAMENTO DE SARA}

No início do tratamento, Sara tinha uma postura infantilizada e movimentos pouco harmoniosos (como se o corpo estivesse "solto"). Apresentava vocabulário empobrecido, visão fragmentada dos fatos, dificuldade para responder a questões sobre sua vida e seus sentimentos, pouca percepção de si e do mundo. Não sabia ler, escrever ou resolver operaçooes matemáticas. No entanto os testes de inteligências revelaram inteligência dentro da média.

Diante disso, o trabalho com Sara teve como eixo norteador o desenvolvimento da percepção do esquema corporal, com o consequente reconhecimento de si como sujeito inserido num contexto social. Pretendeu-se também o desenvolvimento da maturidade emocional. Com isso, esperou-se que ela tivesse uma melhora na forma de compreender o mundo e, assim, na aprendizagem.

Além disso, buscou-se, conforme sugere Jerusalinsky (2002), introduzir questionamentos e conflitos cognitivos, linguísticos e, ou, psicomotores, de acordo com as condiçôes instrumentais da criança, criando-se condições propícias para que ela pudesse estabelecer novas estratégias e elaborar esquemas mais complexos. O objetivo era fazer com que ela se precipitasse, se implicasse como sujeito do acontecimento, aquele responsável por si e pelo que faz de si; evidentemente respeitando-se as limitaçôes trazidas pela idade cronológica e pelas limitações orgânicas da doença. Para tanto, foi de extrema importância a avaliação do estado de desenvolvimento de Sara realizada inicialmente, a fim de que não se fizessem intervenções inócuas, por estarem muito além ou muito aquém de suas necessidades e possibilidades imediatas.

Outra proposta do trabalho desenvolvido foi buscar estabelecer com a mãe (já que o pai nunca compareceu ao tratamento) um modo de encontrar a singularidade da criança, na busca de inseri-la no contexto familiar como um sujeito dotado de desejos. E, mais que isso, fazer com que Sara se percebesse incluída nesse contexto, sendo alguém de importância e singularidade, descolando o sujeito do diagnóstico; ela não era mais um coração doente.

No decorrer do tratamento, muitos fatos revelam a redoma colocada sobre Sara e seu distanciamento imaginário do grupo familiar, mas um episódio mereceu destaque: durante a aplicação do HTPF, na fase diagnóstica do tratamento, Sara não se desenhou no desenho da família. Ao ser questionada se faltava alguém no desenho, respondeu prontamente: "Sim, a cachorrinha". Podemos pensar que, por Sara ter passado por vários problemas de saúde e ter tido risco de morte, a família pode ter desenvolvido, como defesa, uma espera/preparação para sua morte/não existência na família. Esse sentimento pode ter sido percebido, em nível inconsciente, pela criança. Propiciar um ambiente adequado para que 
pudesse surgir o sujeito camuflado pela doença e seu prognóstico foi, pois, um grande objetivo.

Para tanto, Sara precisava ultrapassar a barreira imposta por um coração que, organicamente, mas, principalmente, imaginariamente a impedia de viver como as outras pessoas. Ela percebeu essa fragilidade e se mobilizou para o enfrentamento da situação. Numa sessão, Sara desenhou um coração bem grande em sua folha. A terapeuta lhe perguntou:

T- Como está esse coração?

$S$ - Está ruim... Está fraco.

T- Temos que fazer algo para ajudar esse coração a melhorar e ficar mais forte.

Sara começou a fazer contornos no coração. O coração ficava cada vez mais grosso. Era como se ela se fortalecesse a cada traço no papel.

Aos poucos, a menina começou a perceber-se como Sara, dotada de um corpo, de desejos e sonhos. Percebeu que a doença orgânica não a impedia verdadeiramente de fazer muitas das coisas que não fazia. Percebeu também que estava viva e que não iria morrer a qualquer momento. A partir disso, pôde estabelecer planos para o futuro.

Certa vez, desenhou uma casa. Pediu que a terapeuta também desenhasse uma casa. Comparou os desenhos e disse que, como o da terapeuta estava mais bonito, aquela seria sua casa. Falou que, quando crescesse teria uma casa somente dela [...] Uma casa de dois andares, com banheira e sala grande. Disse ainda que seria professora. Temos com essa fala a percepção de que Sara começou a se diferenciar da doença e passou a estabelecer conexões entre seus desejos e suas possibilidades futuras.

Ao longo do tratamento, como já exposto anteriormente, a mãe de Sara deixou de chamá-la de "meu bebê", passando a chamá-la de "bebezão" e, por fim, de "mocinha". A "mocinha" agora era responsável por sua agenda, por seus deveres de casa, por seus objetos pessoais, pela arrumação de sua cama e por alguns outros atributos de cuidado doméstico. Começou a falar e brincar de forma menos infantilizada, inclusive não aceitando as brincadeiras com músicas que falassem sobre o corpo, que antes muito lhe agradavam. Sara já não era mais um bebê, ou um bebezão [...] Era uma mocinha, dotada de sonhos para o futuro e ciente da necessidade de se esforçar para se desenvolver. Ela agora era capaz de tomar a palavra e falar de si e de seus desejos, inclusive indo contra 
o desejo da mãe: "Minha mãe disse para eu faltar de aula hoje porque só vai ter uma hora de aula. Mas já disse para ela que não quero faltar. Eu tenho que ir à escola porque vai ter 'para casa' e eu não posso perder. Não quero ficar de recuperação”. Como bem enuncia Jerusalinsky (2002), algo de belo surge quando, perante a imposição das limitaçooes orgânicas e diante do determinismo simbólico do discurso dos pais, uma criança consegue estabelecer uma resposta, abrindo espaço para o aparecimento do seu desejo.

$\mathrm{Na}$ última sessão, antes das férias de dezembro, a terapeuta pediu que Sara fizesse um desenho de si mesma, um retrato. Ela desenha um coração. A terapeuta pergunta se ela é um coração. Sara olha o desenho e diz: "Oh [...] não, também tenho cabeça, pernas e braços". E desenhou, completando o coração. A figura 1 apresenta o desenho feito por Sara.

Figura 1. Desenho feito por Sara em sessão de atendimento psicoterápico

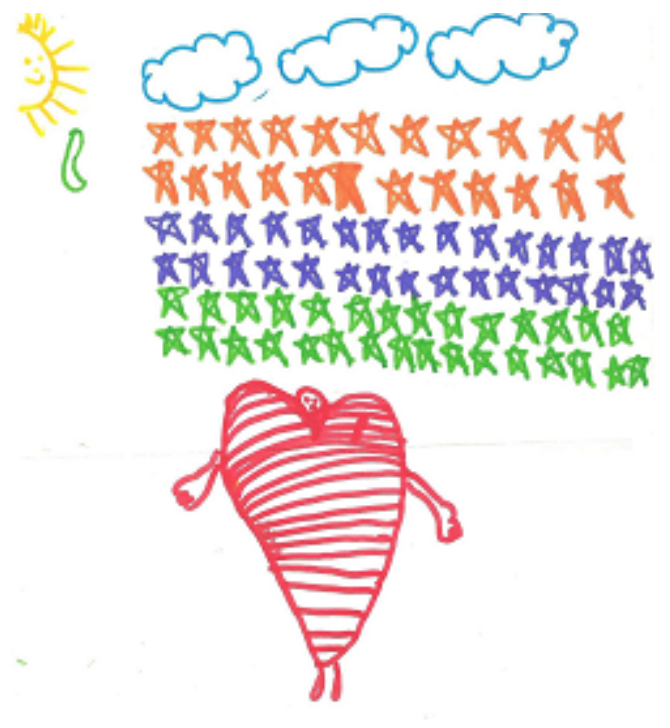

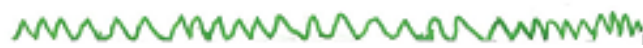

Fonte: dados da pesquisa.

Levará um bom tempo para que o coração de Sara, expresso no desenho, "diminua", emergindo a Sara como dotada de outros órgãos, outras possibilidades, de sonhos e de futuro. No entanto, a sua resposta foi um marco importante em sua diferenciação da doença: ela não é mais a cardíaca, ela não é mais um coração. 
Transformar um pedaço de carne num sujeito desejante, produzir um deslocamento na posição de objeto a ser manejado por um outro, para implicar o que é dito com sobre quem é dito: esse é um dos objetos da psicoterapia de uma criança que nasce com uma doença orgânica grave. 


\section{REFERÊNCIAS}

Battikha, E. C., Faria, M. C. C. \& Kopelman, B. J. (2007). As representações maternas acerca do bebê que nasce com doenças orgânicas graves. Psicologia: Teoria e Pesquisa, 23(1), 17-24.

Brauer, J. F. (1994). Atendimento individual na estrutura familiar: uma experiência de transmissão da psicanálise a partir da universidade. In J. F. Brauer, A criança no discurso do outro, um exercício de psicanálise. (pp. 15-24). São Paulo: Iluminuras.

Carter, B. \& McGoldrick, M. (1995). As mudanças no ciclo de vida familiar: uma estrutura para a terapia familiar. Porto Alegre: Artmed.

Castro, D. A. (2001). Psicologia e ética em cuidados paliativos. Psicologia, Ciência e Profissão, 21, 44-51.

Faria, M. R. (1994). Análise... de quem? As entrevistas preliminares no atendimento de crianças. In J. F. Brauer, $A$ criança no discurso do outro: um exercício de psicanálise. (pp. 37-48). São Paulo: Iluminuras.

Jerusalinsky, J. (2002). Enquanto o futuro não vem: a psicanálise na clínica interdisciplinar com bebês. Salvador: Álgama.

Lacan, J. (1978). A instância da letra no inconsciente ou a razão desde Freud. In J. Lacan, Escritos. (p. 226). São Paulo: Perspectiva.

Kruel, C. S. \& Lopes, R. C. S. (2012). Transição para a parentalidade no contexto da cardiopatia congênita do bebê. Psicologia: Teoria e Pesquisa, 28(1), 35-43.

Pavone, S. \& Abrão, L. V. (2014). Quando um déficit ou doença orgânica bate à porta do imaginário parental: os efeitos na constituição subjetiva da criança. Distúrbios da Comunicação, 26(2), 373-385.

Reze, B. (2006). Cardiopatia infantil: implicações na relação entre mãe e filho. Psicologia Revista, 15(1), 11-20.

Ribeiro, C. \& Madeira, A. M. F. (2006). O significado de ser mãe de um filho portador de cardiopatia: um estudo fenomenológico. Revista da Escola de Enfermagem da USP, 4O(1), 42-49.

Tavares, K. O., Carvalho, M. D. B. \& Pelloso, S. M. (2014). Dificuldades vivenciadas por mães de pessoas com fibrose cística. Texto e Contexto Enfermagem, 23(2), 294-300. 
Vorcaro, A. (1997). A criança na clínica psicanalitica. Rio de Janeiro: Companhia de Freud.

Vorcaro, A. (1998). Doenças graves na infância. In: Trata-se uma criança: anais do Congresso Internacional de Psicanálise e suas conexóes. Rio de Janeiro: Companhia de Freud. 